\title{
New Synthetic Route to Copoly(Ester-Thioester)s by Direct Polycondensation of Thio-Acids with Diols of Cycloketones Derivatives
}

\author{
Nayef S. Al-Muaikel \\ Chemistry Department, College of Science, Aljouf University, Al-Jouf, Saudi Arabia \\ Email: n_almuaikel@hotmail.com
}

Received 13 December 2015; accepted 11 April 2016; published 14 April 2016

Copyright (C) 2016 by authors and Scientific Research Publishing Inc.

This work is licensed under the Creative Commons Attribution International License (CC BY). http://creativecommons.org/licenses/by/4.0/

\section{(c) (i) Open Access}

\begin{abstract}
A new series of copoly(ester-thioester)s had been synthesized using direct polycondensation technique. These copolythioesters were synthesized by direct polycondensation of 4,4'-(terephthaloyIdithio) diacetic acid I, 3,3'(isophthaloyl-dithio) diacetic acid II, or 1,8 (sebacoyldithio) diacetic acid III, with 2,6-bis(p-hydroxybenzylidene) tert. butyl cyclohexanone IV and 2,6-divanylidene tert. butyl cyclohexanone $V$, using a condensing agent consisting of pyridine-thionyl clhloride complex. The resulting copolymers were characterized by elemental and spectral analyses, solubility, viscometery, electronic spectra and thermogravimietric analyses. The crystallinity of some copolymers was examined by X-ray diffraction analyses. Furthermore, the morphology of selec ted examples of the copolymers was examined by scanning electron microscopy.
\end{abstract}

\section{Keywords}

Synthesis, Characterization, Copoly(Ester-Thioester)s, Polycondensation, Cycloketones

\section{Introduction}

Engineering plastics containing sulfur atoms, such as poly(phenylenesulfide), poly(ethersulfone), and polysulfone have been put into practical use because they have superior mechanical properties and excellent resistance to heat and chemicals. Thus, the incorporation of sulfur into polymers is expected to result in improved properties, including mechanical properties and resistance to heat and chemicals. Since the number of studies on linear polymers containing sulfur atoms has been increasing. For example, Kobayashi et al. [1] [2] study the polyaddi- 
tion reaction of dithiols to dialkenes and to dialkynes. Sato et al. [3]-[5] also study polyaddition of dithiols to bis(alkoxyallene)s or diallenylbenzene. Koizumi et al. [6] synthesize polysulfide by the polyaddition reaction of dithiol and epoxide. The syntheses of polythioesters by interfacial polycondensation of aromatic and aromaticaliphatic dithiols with aromatic and aliphatic acid dichlorides have been reported by Podkoscielny et al. [7]-[12] . Shaffer and Percec [13] find that polythioethers and copolythioethers with methylene numbers of 2 - 10 derive from 4,4'-biphenyldithiol and $\alpha, \beta$-dibromoalkanes exhibite thermotropic liquid crystalline characteristics.

The work reported here outlines the synthesis of copoly(ester-thioester)s by direct polycondensation of new dithio acids with 2,6-bis(p-hydroxybenzylidene) tert. butyl cyclohexanone and 2,6-divanylidene tert. butyl cyclohexanone using a condensing catalyst based on a pyridine-thionyl chloride complex. Furthermore, our interest is focused upon studying the effect of the ester-thioester linkage on polymer properties, especially thermal stability and crystallinity.

\section{Experimental}

\subsection{Measurements}

Elemental analyses were carried out using an Elemental Analyses System GmbH, VARIOEL, V2.3 July 1998 CHNS Mode. IR spectra were recorded on FT-IR-470, Infrared spectrophotometer, Shimadzu by using the KBr pellet technique. The 1H-NMR spectra were recorded on a GNM-LA 400-MHz NMR spectrophotometer at room temperature in DMSO or $\mathrm{CDCl}_{3}$ using TMS as the internal reference. Inherent viscosities of polymer solutions $(0.5 \% \mathrm{w} / \mathrm{v})$ in DMSO were determined at $30^{\circ} \mathrm{C}$ using an Ubbelohde suspended level viscometery. The solubility of polymers was examined using $0.02 \mathrm{~g}$ of polymer in $3-5 \mathrm{ml}$ of solvent at room temperature. The Xray diffractographs of the polymers were obtained with a Philips X-ray PW1710 diffractometer, and Ni-filtered $\mathrm{CuK} \alpha$ radiations. Thermogravimetric analysis (TGA) and differential thermal gravimetric (DTG) were carried out in air with Shimadzu DTG-60 at heating rate of $10^{\circ} \mathrm{C} / \mathrm{min}$. in air. The morphology of a selected example of copolymer was examined by SEM (Jeol JSM-5400 LV instrument). The SEM sample was prepared by evaporating a dilute solution of polymer on a smooth surface of aluminium foil, and subsequently coating it with gold palladium alloy. SEM images were taken on a Pentaz Z-50 P Camera with Ilford film at an accelerating voltage of $15 \mathrm{KV}$ using a low dose technique [14].

\subsection{Reagents and Solvents}

Tert.butyl-cyclohexanone (Merck, 99\%). Thioglycolic acid (Merck, 99\%), p-hydroxybenzaldehyde (Aldrich) and 4-hydroxy-3-methoxybenzaldehyde (vanillin) (Aldrich) were used without crystallization. Terephthaloyl chloride (Aldrich) was recrystallized from n-hexane (m.p. $83^{\circ} \mathrm{C}-84^{\circ} \mathrm{C}$ ). Isophthaloyl chloride (Aldrich) was recrystallized from n-hexane (m.p. $44^{\circ} \mathrm{C}$ ). Sebacoyl dichlorides were freshly distilled at $182^{\circ} \mathrm{C} 116$ Torr was used. Sodium hydroxide was analytical grade. All other chemicals used were of high purity following purification by standard methods [15].

\subsection{Monomer Syntheses}

\section{Synthesis of Dithio-acids: I-III}

\section{General Procedure}

A mixture of thioglycolic acid $(0.2 \mathrm{~mol})$ and a solution of sodium hydroxide $(0.25 \mathrm{~mol})$ was stirred at $25^{\circ} \mathrm{C}$. After siring, a solution of $0.1 \mathrm{~mol}$ of the appropriate diacid chlorides in $20 \mathrm{ml}$ tetrahydrofurane (THF) was added in a drop wise manner within $30 \mathrm{~min}$. At the end of the reaction time, a white solid was precipitated out and then acidified with $0.1 \mathrm{M} \mathrm{HCl}$. The solid product was filtered off, washed with water, air dried and recrystallized from the appropriate solvent.

i) Synthesis of 4,4'-(Terephthaloyldithio) Diacetic Acid I

This dithio acid was obtained by the reaction of thioglycolic acid with terephthaloyl chloride and recrystallized from (acetic acid-water) (1:l) as white crystals in $95 \%$ yield, m.p. $242^{\circ} \mathrm{C}-243^{\circ} \mathrm{C}$. Analytically calculated for $\mathrm{C}_{12} \mathrm{H}_{10} \mathrm{O}_{5} \mathrm{~S}_{2}$ : C, 45.86; H, 3.18; S, 20.38. Found: C, 45.79; H, 3.08; S, 20.31. FT-IR (KBr) showed at 3420 $\mathrm{cm}^{-1}$ (b, OH), at $1720 \mathrm{~cm}^{-1}$ (s, $\mathrm{C}=\mathrm{O}$ of thioester group) and at $1680 \mathrm{~cm}^{-1}$ (s, $\mathrm{C}=\mathrm{O}$ of $-\mathrm{COOH}$ group). ${ }^{1} \mathrm{H}$ NMR (DMSO- $\left.d_{6}, 600 \mathrm{MHz}\right) \delta 7.95-8.15(\mathrm{~m}, 4 \mathrm{H}, \mathrm{Ar}-\mathrm{H}), 7.55$ (m, 2H, OH groups) and 3.85 (s, $4 \mathrm{H}$ of $2\left(\mathrm{CH}_{2}\right)$ ). 


\section{ii) Synthesis of 3,3'(Isophthaloyldithio) Diacetic Acid II}

This dithio acid was obtained by the reaction of thioglycolic acid with isophthaloyl chloride and recrystallization from (ethanol-water) $(1: 1)$ as white crystals in in $89 \%$ yield, m.p. $198^{\circ} \mathrm{C}-199^{\circ} \mathrm{C}$. Analytically calculated for $\mathrm{C}_{12} \mathrm{H}_{10} \mathrm{O}_{5} \mathrm{~S}_{2}$ : C: 45.86; H, 3.18; S, 20.38. Found: C, 45.73; H, 3.11; S, 20.29. IR (KBr) showed at $3385 \mathrm{~cm}-\mathrm{I}(\mathrm{b}$, $\mathrm{OH}$ ), at $1715 \mathrm{~cm}^{-1}$ (s, C=O of thioester) and at $1675 \mathrm{~cm}^{-1}$ (m, C=O of -COOH group). 1H NMR (DMSO-d, 400 MHz) $\delta 8.15$ - 8.30 (m, 4H, Ar-H), 7.6 - 785 (m, 2H, OH group) and 4.0 (s, $4 \mathrm{H}$ of 2( $\left.\mathrm{CH}_{2}\right)$ ).

\section{iii) Synthesis of 1,8(Sebacoy Jdithio) Diacetic Acid III}

This dithio acid was obtained by the reaction of thioglycolic acid with sebacoyl chloride and recrystallization from (acetic acid-water) (1:l) as white crystals in $85 \%$ yield, m.p. $105^{\circ} \mathrm{C}-106^{\circ} \mathrm{C}$. Analytically calculated for $\mathrm{C}_{14} \mathrm{H}_{22} \mathrm{O}_{6} \mathrm{~S}_{2}$ : C, 48.00; H, 6.29; S, 18.29. Found: C, 47.91; H, 6.25; S, 18.19. IR (KBr) showed at $3350 \mathrm{~cm}^{-1}$, (b, $\mathrm{OH}$ ), at $2950 \mathrm{~cm}^{-1}$ (m, C-H aliphatic), at $1720 \mathrm{~cm}^{-1}$ (C=O of thioester group) and at $1675 \mathrm{~cm}^{-1}$ (C=O of -COOH group). 1H NMR (DMSO-d 6 , $400 \mathrm{MHz}) \delta 8.25 \mathrm{ppm}\left(\mathrm{S}, 2 \mathrm{H}\right.$ of OH), at $4.35 \mathrm{pprn}\left(\mathrm{S}, 4 \mathrm{H}\right.$ of $\left.2\left(\mathrm{CH}_{2}\right)\right)$, at $3.25 \mathrm{ppm}$ (m, $4 \mathrm{H}$ of $2\left(\mathrm{CH}_{2}-\mathrm{CO}-\right)$ ), and at $2.75-2.95 \mathrm{ppm}\left(\mathrm{m}, 12 \mathrm{H}\right.$ of $\left.6-\mathrm{CH}_{2}-\right)$.

iv) Synthesis of 2,6-Bis(p-hydroxybenzylidene) tert. but. cyclohexanone IV

A mixture of (2.44 g, 0.2 mole) 4-hydroxy-benzaldehyde and (1.54 g, 0.1 mole) tert. but. cyclohexanone was dissolved in $100 \mathrm{ml}$ ethanol at $50^{\circ} \mathrm{C}$. The mixture was stirred while dry $\mathrm{HCl}$ gas was introduced as a catalyst. After two hrs of stirring, a solid product separated out, which was filtered off, washed with excess water, dried and recrystallized twice from methanol as greenish yellow crystals; in $94 \%$ yield, m.p. $120^{\circ} \mathrm{C}-121^{\circ} \mathrm{C}$. Anal. Calcd. for $\mathrm{C}_{21} \mathrm{H}_{20} \mathrm{O}_{5}$ : C, 71.58; H, 5.72. Found: C, 71.43; H, 5.63.

v) Synthesis of 2,6-Divanillylidene tert. but. cyclohexanone $\mathrm{V}$

A mixture of (3.04 g, 0.2 mole) 4-hydroxy-3-methoxybenzaldehyde and ( $1.54 \mathrm{~g}, 0.1 \mathrm{~mole}$ ) tert. but. cyclohexanone was dissolved in $100 \mathrm{ml}$ ethanol at $50^{\circ} \mathrm{C}$. The mixture was stirred while dry $\mathrm{HCl}$ gas was introduced as a catalyst. After two hrs of stirring, a solid product separated out, which was filtered off, washed with excess water, dried and recrystallized twice from methanol as greenish yellow crystals; in $92 \%$ yield, m.p. $108^{\circ} \mathrm{C}$ $109^{\circ} \mathrm{C}$. Anal. Calcd. for $\mathrm{C}_{21} \mathrm{H}_{20} \mathrm{O}_{5}$ : C, 71.58; H, 5.72. Found: C, 71.43; H, 5.63.

\subsection{Synthesis of Copolythioesters VI-XI}

In a three-necked flask, in an ice bath, equipped with a mechanical stirrer (2000 rev $\left.\cdot \mathrm{min}^{-1}\right), 11 \mathrm{mmol}$ of cold thionyl chloride were introduced. Pyridine $(15 \mathrm{ml})$ was added slowly, to keep the reaction temperature low, and the mixture was stirred for $40 \mathrm{~min}$. At the end of this time a mixture of the monomers in pyridine $(25 \mathrm{ml})$ was added dropwise over $30 \mathrm{~min}$. The cooling bath was removed and the resulting mixture was maintained at room temperature for $30 \mathrm{~min}$. It was then heated at $80^{\circ} \mathrm{C}$ for $5 \mathrm{~h}$ until a deep brownish solution formed. The brown solution was poured into a mixture of methanol-water (1:1) when the polymers precipitated. The product was filtered off, washed with water, dilute $\mathrm{HCl}$, hot acetone and hot ethanol, and finally dried under reduced pressure $\left(1 \mathrm{mmHg}\right.$ ) at $90^{\circ} \mathrm{C}$ for 2 days. Table 1 summarizes the yield and elemental analysis of the various copolythioesters.

Table 1. Elemental analyses, inherent viscosity and yield of copolythioesters VI-XI.

\begin{tabular}{|c|c|c|c|c|c|c|c|c|c|}
\hline \multirow{2}{*}{$\begin{array}{c}\text { Polymer } \\
\text { Code }\end{array}$} & \multirow[t]{2}{*}{ Repeating unit } & \multicolumn{2}{|c|}{$\mathrm{C} \%$} & \multicolumn{2}{|c|}{ H\% } & \multicolumn{2}{|c|}{ S\% } & \multirow{2}{*}{ 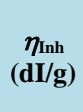 } & \multirow{2}{*}{ Yield (\%) } \\
\hline & & Calcd. & Found & Calcd. & Found & Calcd. & Found & & \\
\hline VI & $\mathrm{C}_{38} \mathrm{H}_{35} \mathrm{O}_{7} \mathrm{~S}_{2}(667)$ & 68.37 & 68.98 & 5.25 & 5.07 & 9.60 & 9.21 & 0.73 & 78 \\
\hline VII & $\mathrm{C}_{40} \mathrm{H}_{39} \mathrm{O}_{9} \mathrm{~S}_{2}(727)$ & 66.02 & 65.16 & 5.36 & 5.09 & 8.80 & 8.03 & 0.65 & 83 \\
\hline VIII & $\mathrm{C}_{38} \mathrm{H}_{35} \mathrm{O}_{7} \mathrm{~S}_{2}(667)$ & 68.37 & 68.03 & 5.25 & 5.01 & 9.60 & 9.11 & 0.68 & 75 \\
\hline IX & $\mathrm{C}_{40} \mathrm{H}_{39} \mathrm{O}_{9} \mathrm{~S}_{2}(727)$ & 66.02 & 65.32 & 5.36 & 5.01 & 8.80 & 8.22 & 0.89 & 82 \\
\hline $\mathbf{X}$ & $\mathrm{C}_{40} \mathrm{H}_{47} \mathrm{O}_{7} \mathrm{~S}_{2}$ (703) & 68.28 & 67.51 & 6.69 & 6.24 & 9.10 & 8.41 & 0.43 & 64 \\
\hline XI & $\mathrm{C}_{42} \mathrm{H}_{51} \mathrm{O}_{9} \mathrm{~S}_{2}(763)$ & 66.05 & 65.24 & 6.68 & 6.11 & 8.39 & 8.13 & 0.35 & 78 \\
\hline
\end{tabular}

${ }^{*} \eta$ Inherent viscosity measured in DMSO at $30^{\circ} \mathrm{C}$. 


\section{Results and Discussion}

A literature survey reveals that the direct polycondensation of dicarboxylic acids with bisphenols in thionyl chloride and pyridine has been reported to produce high molecular weight polyesters [16]-[18]. Using this information, we developed a method for the preparation of new polythioesters of diarylidenecyclohexanone based on the direct polycondensation of new dithio acids (I-III) and 2,6-bis(p-hydroxybenzylidene) tert. but. cyclohexanone IV or 2,6-divanillyidene tert. but. cyclohexanone V. The new dithio acids were easily prepared from the interaction of $2 \mathrm{~mol}$ of thioglycolic acid with $1 \mathrm{~mol}$ of diacid chlorides in a sodium hydroxide Solution according to Scheme 1.

The structure of these dithio acids I-III was established from elemental, FT-IR and NMR spectral analyses. Attempts to prepare the corresponding diacid chlorides from the dithio acids I-III, failed. This could be attributed to the instability of these acid chlorides. This observation encouraged us to apply the direct polycondensation technique using thionyl chloride and a pyridine complex to produce the new copolythioesters (VI-XI) as depicted in Scheme 2. The structure of the resulting polythioesters was established from elemental and FT-IR analyses. The FT-IR spectra of all the polythioesters showed the disappearance of the hydroxyl groups and the<smiles>O=C(O)COC(=O)CSCC(=O)SCC(=O)SCC(=O)O</smiles>

Scheme 1. Synthesis of dithio acids: I-III.<smiles>[R]c1cc(/C=C2\CC(C(C)(C)C)C/C(=C\c3ccc(O)c(POC(=O)CSC(=O)PC(=O)SCC(=O)O)c3)C2=O)ccc1O</smiles><smiles>[R]c1cc(/C=C2\CC(C(C)(C)C)C/C(=C\c3ccc(OC(=O)CSC(=O)PC(=O)SC(C)(C)C)c([3H])c3)C2=O)ccc1O[Ga]</smiles>

\section{VI-XI}
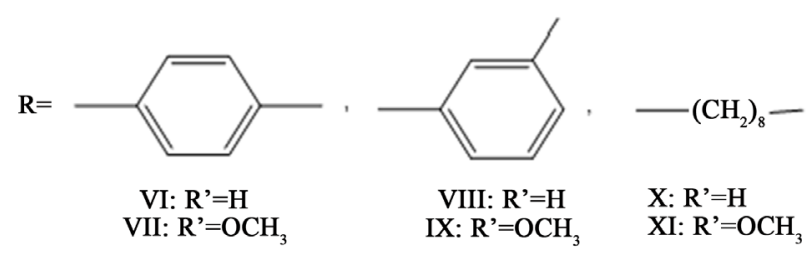

Scheme 2. Synthesis of copolythioesters VI-XI. 
appearance of absorption bands at $1745-1750 \mathrm{~cm}^{-1}$ ( $\mathrm{C}=\mathrm{O}$ of ester group), at $1720-1725 \mathrm{~cm}^{-1}$ ( $\mathrm{C}=\mathrm{O}$ of thioester), at $1665-1670 \mathrm{~cm}^{-1}$ (C=O of tert. but. cyclohexanone), at $1580-1600 \mathrm{~cm}^{-1}$ (C=C stretching) and at 1410 $1445 \mathrm{~cm}^{-1}$ (- $-\mathrm{CH}_{2}$-S-groups). This was in addition to the other characteristic absorption bands for the rest of the macromolecule. The elemental analysis of all the different copolythioester coincided with the characteristic repeating units of each polymer, which reveals the introduction of two new sulphur atoms in the repeating unit. These data are included in Table 1.

\section{Polymer characterization}

\section{Viscosity}

The inherent viscosities $\left(\eta_{\text {inh }}\right)$ of copolythioesters VI-XI were determined in DMSO at $30^{\circ} \mathrm{C}$ with an Ubbelohde suspended level viscometer The inherent viscosity value is defined as:

$$
\eta_{\text {inh }}=\left[2.3 \log \eta / \eta_{o}\right] / \mathrm{C}
$$

The solution concentration $\mathrm{C}$ is $0.5 \mathrm{~g} / 100 \mathrm{ml}, \eta / \eta_{\mathrm{o}}=$ relative viscosity (or viscosity ratio). It can be shown from Table 1 that copolythioester IX had high inherent viscosity $(0.89 \mathrm{dL} / \mathrm{g})$ and this may be attributed to high molecular weight of the polymer. But, the inherent viscosity of the copolythioester XI $(0.35 \mathrm{dL} / \mathrm{g})$ this may be attributed to low molecular weight of this copolythioester.

\section{Solubility}

The solubility behavior of all copolythioesters VI-XI is summarized in Table 2. A 10\% (w/v) solution was taken as a criterion for solubility). It was found that all the polymers dissolved readily in concentrated $\mathrm{H}_{2} \mathrm{SO}_{4}$ at room temperature giving an intense blue solution. Copolythioesters which contain methylene linkage, i.e. $-\left(\mathrm{CH}_{2}\right)_{8}-(\mathrm{X}, \mathrm{XI})$ are more soluble in DMSO or NMP than are other polymers. Almost all copolythioesters were soluble in both polar aprotic solvents, such as NMP, and DMSO, and less polar solvents, including; acetonechloroform mixture and THF except copolythioesters, VIII and IX were partially soluble in less polar solvents. Generally, the presence of ester-thioester linkage in the polymer main chain led to slight increases in the solubility of the polythioesters.

\section{Electronic Spectra:}

The electronic spectra of copolythioesters VI-XI were obtained in DMSO at a concentration of $2.6 \times 10^{-6} \mathrm{M}$. These displayed two absorption bands with $\lambda_{\max }$ near $263 \mathrm{~nm}$, which was due to the $\pi-\pi^{*}$ transition within the benzenoid system, and with $\lambda_{\max }$ near $365 \mathrm{~nm}$, which was due to the $\pi-\pi^{*}$ excitation of $\mathrm{C}=\mathrm{O}$ or $\mathrm{C}=\mathrm{S}$ groups. The electronic spectra of copolyesters VI-XI show broadening absorption bands and a small bathochromic shifting of both bands, indicating a highly conjugated system. Moreover, the electric conducting properties of the undoped and doped polymers are therefore related to the presence of extensively delocalized $\mathrm{p}$ electrons along the polymer chain, and the delocalization of $\pi$ electrons also contributes to the formation of the polymer-iodine adducts.

\section{Scanning Electron Microscopy Measurements}

The morphology of the synthesized copolythioester VII (as example) was examined by scanning electron microscopy (SEM). This technique gives us the ability to show the surface of the polymers and to study the effect of structure on the surface of the selected polymer by comparison the images in each case. The study of selected copolythioester VII showed that the surface of that polymer VII (Figure 1(a) and Figure 1(b) magnification X = 2000, $X=5000$ ) consisted of porous kidney shape accumulative merged particles, with higher magnification $X$ $=10,000$ and $X=15,000$ (Figures 1 (c)-(e)) showed that the globular and subglobular structures, like sponge, appeared in a continuous chain with some coalescence present.

Table 2. Solubility characteristics of copolythioesters VI-XI.

\begin{tabular}{cccccccc}
\hline Polymer Code & DMSO & DMF-DMA (1:1) & NMP & Chloroform Acetone (1:1) & THF & Methylene Chloride & H $_{2}$ SO \\
4
\end{tabular}

(+) Soluble at room temperature RT; ( \pm ) Partially soluble at RT; (-) Insoluble. 


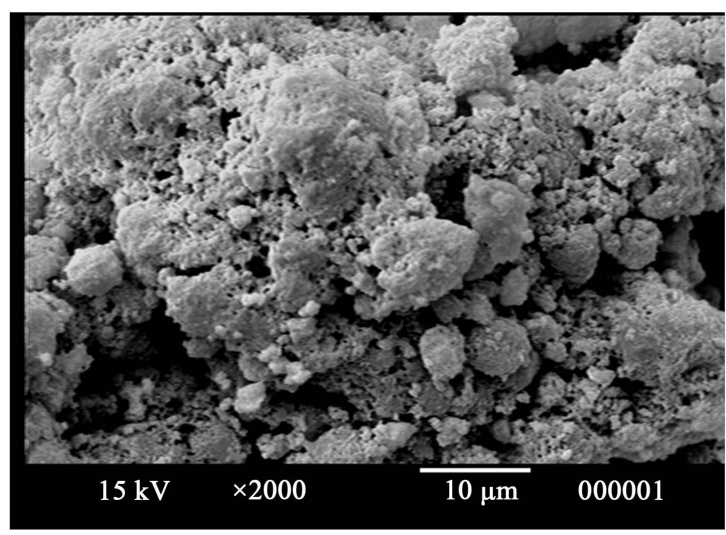

(a)

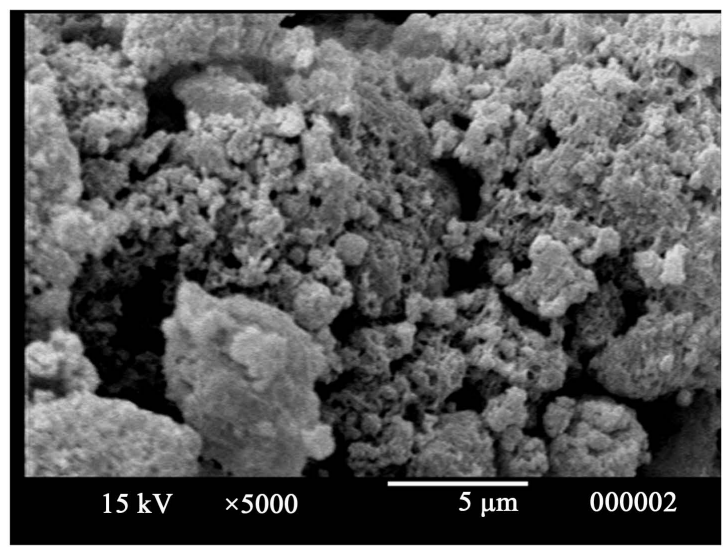

(b)

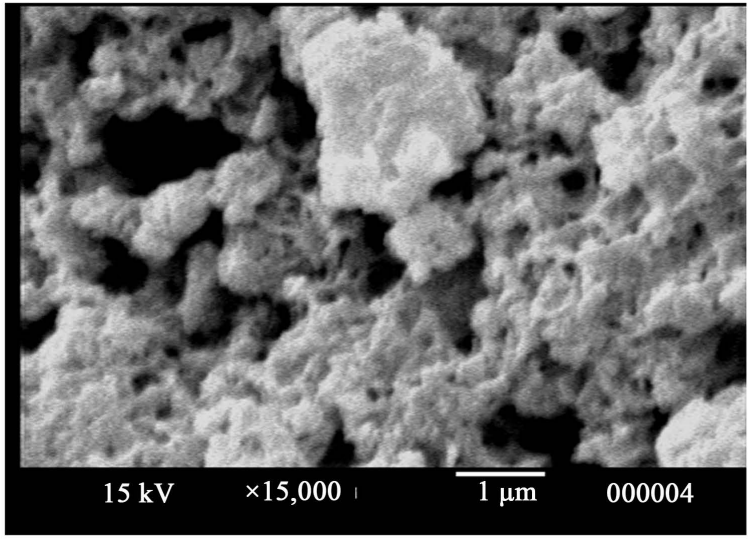

(d)

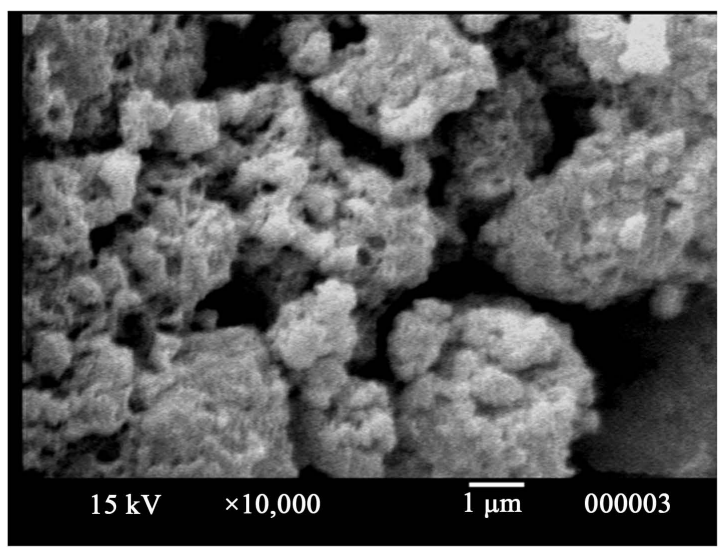

(c)

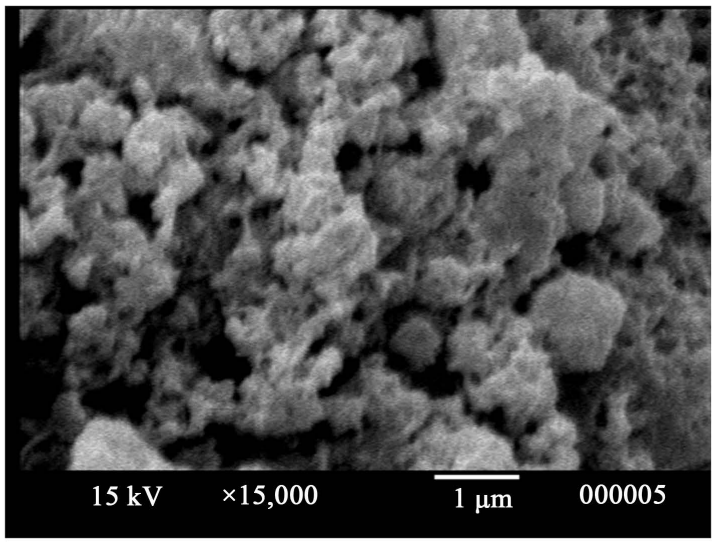

(e)

Figure 1. SEM images of copolythioester VI surface at different magnifications, (a): $x=2000$; and (b): $x=5000$; (c): $x$ $=10,000$; and $(d) x=15,000 ;(e): x=15,000$.

\section{X-ray Analysis}

The X-ray diffractogram of copolythioesters VI-XI containing 4-teriary butyl-cyclohexanone unit in Figure 2 and Figure 3 (as example) show a few reflection peaks that are intermediate between crystalline and amorphous interference in the region $2 \theta=5^{\circ}-60^{\circ}$. This indicates that there is a large class of structures that are intermediate in the ordered states between crystals (with pronounced long-range order) in the arrangement of their atoms and molecules. Moreover, the presence of high $\mathrm{C}=\mathrm{C}$ bond and $\mathrm{C}=\mathrm{S}$ levels induces some order between two adjacent chains in the polymer, leading to some extent of crystallinity. More particularly, the presence of 8 


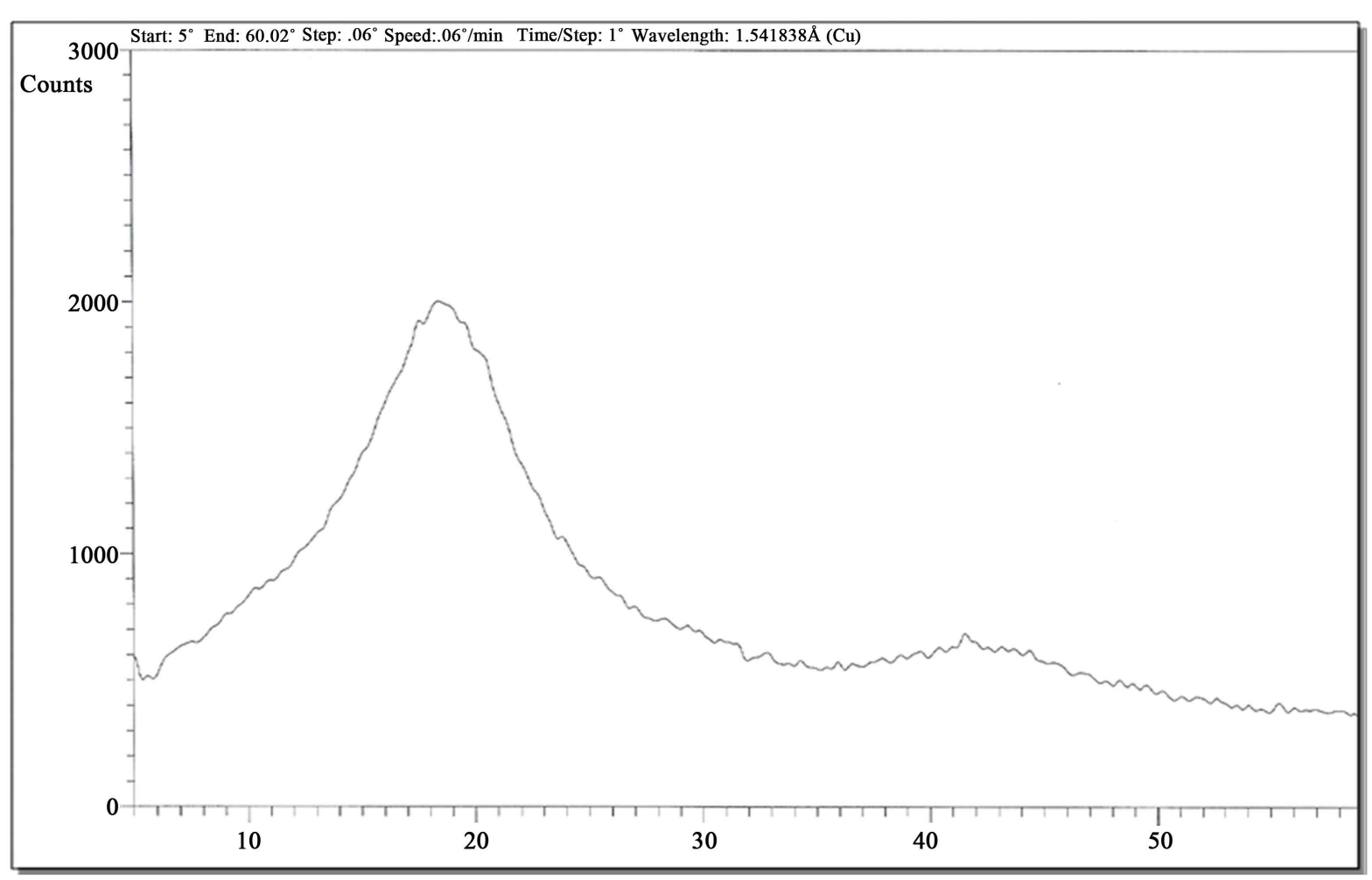

Figure 2. X-ray diffraction pattern of copolythioester VI.

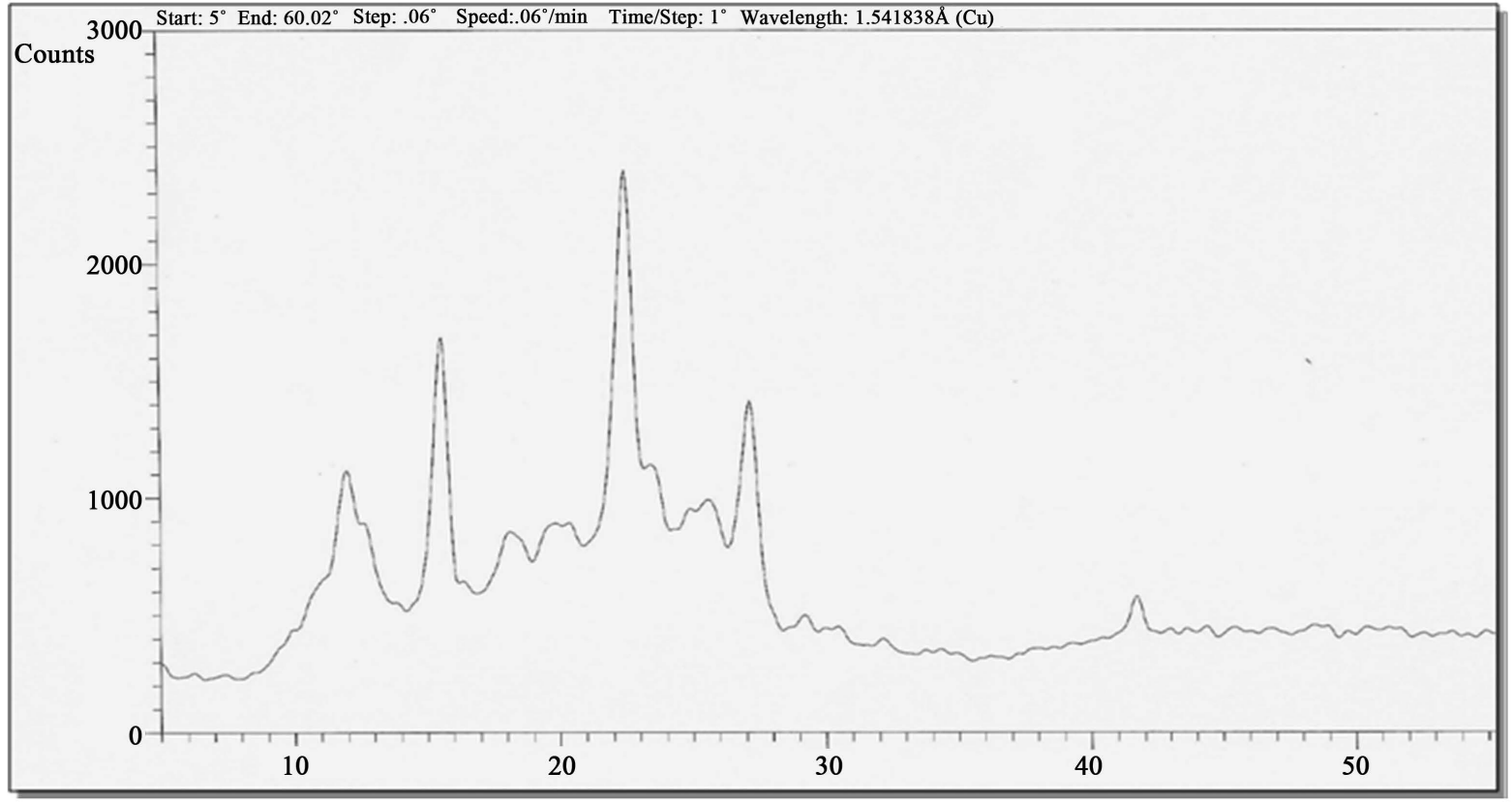

Figure 3 X-ray diffraction pattern of copolythioester X.

methylene groups as in copolythioester $\mathrm{X}$ as flexible chain, led to some crystalinity as shown in Figure 3, compared with copolythioester VI.

Thermogravimetric Analysis

The thermal properties of copolythioesters VI-XI containing 4-teriary butyl-cyclohexanone unit in the main chain thus obtained, were investigated by thermogravimetric analysis (TGA), DTG and DTA in air at a heating 
rate of $10^{\circ} \mathrm{C} / \mathrm{min}$. The thermographs of these copolythioesters are given in Figure 4 and Figure 5 for copolythioesters VI and XI (as examples), also Table 3 gives the temperature of various percentages of weight loss. The temperature for a $10 \%$ weight loss is considered to be the polymer decomposition temperature and ranges between $325^{\circ} \mathrm{C}$ and $395^{\circ} \mathrm{C}$. In Figure 4, TGA curve of copolythioester VI show a weight loss in the range $8 \%$ $19 \%$ starting at $160^{\circ} \mathrm{C}-200^{\circ} \mathrm{C}$, which may be attributed to loss of absorbed moisture and entrapped solvents. The thermographs also indicate, the polymers decompose in one stage. This stage which is rapid stage between $400^{\circ} \mathrm{C}$ and $430^{\circ} \mathrm{C}$ depends upon the nature of the polymer and copolymers. The rate of degradation in the first stage is somewhat faster than in the second stage. Moreover, the data indicated that the T10, values of polythioesters derived from 1,8(sebacoyldithio) diacetic acid (X, XI) showed somewhat less thermally stable than other polythioesters.

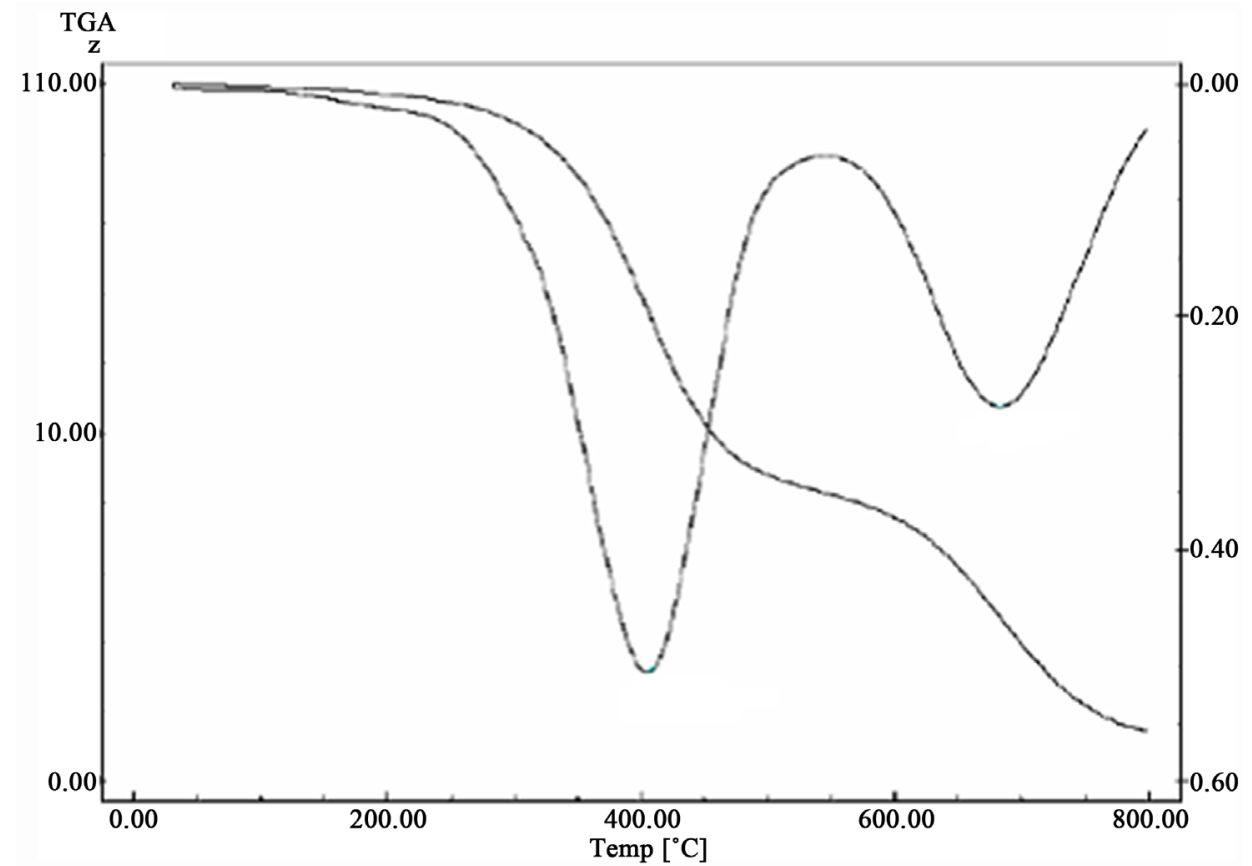

Figure 4. The TGA and Dr TGA traces of copolythioester VI in nitrogen at a heating rate of $10^{\circ} \mathrm{C} / \mathrm{min}$.

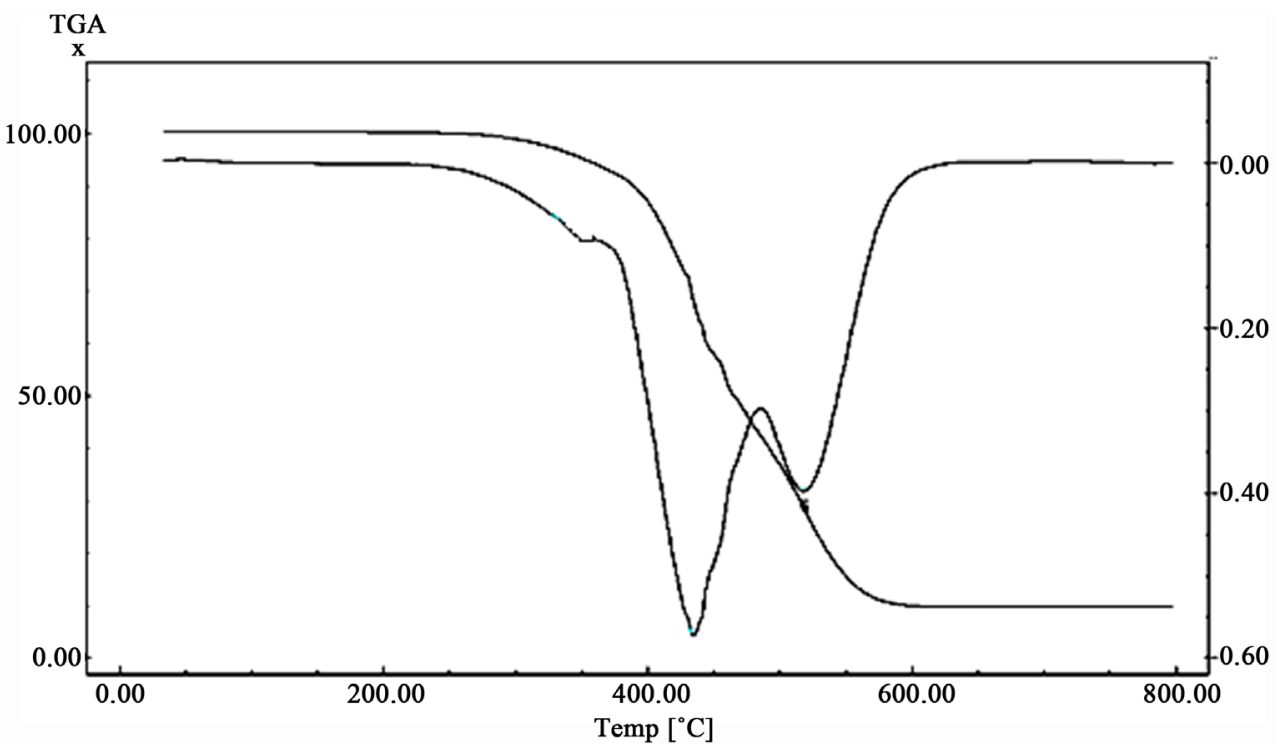

Figure 5. The TGA and Dr TGA traces of copolythioester $\mathrm{X}$ in nitrogen at a heating rate of $10^{\circ} \mathrm{C} / \mathrm{min}$. 
Table 3. Thermal properties of copolythioesters VI-XI.

\begin{tabular}{|cccccc}
\hline Polymer & \multicolumn{5}{c}{ Temperature $\left({ }^{\circ} \mathbf{C}\right)$ for various decomposition levels } \\
\hline Code & $\mathbf{1 0 \%}$ & $\mathbf{2 0 \%}$ & $\mathbf{3 0 \%}$ & $\mathbf{4 0 \%}$ & $\mathbf{5 0 \%}$ \\
\hline VI & 410 & 450 & 455 & 485 & 515 \\
VII & 400 & 425 & 460 & 470 & 485 \\
VIII & 395 & 410 & 430 & 450 & 480 \\
IX & 380 & 405 & 450 & 470 & 495 \\
X & 355 & 385 & 430 & 470 & 475 \\
XI & 320 & 410 & 430 & 450 & 465 \\
\hline
\end{tabular}

*Heating rate: $10^{\circ} \mathrm{C} \min ^{-1}$.

\section{Conclusion}

New copoly(ester-thioester)s based on diarylidene tert. butyl cyclohexanone moiety have been synthesized by direct polycondensation technique. The presence of ester-thioester linkage, beside the aliphatic chains, in the polymer main chain leads to slight increases in the solubility of the polythioesters. X-ray diffraction analyses indicate that the copolythioester $\mathrm{X}$ which contains a flexiable chain has some crystallinity then the other polymers. Thermogravimetric analyses show that copolythioester derived from monomeric unit IV is more thermally stable than those derived from monomeric unit V.

\section{References}

[1] Kobayashi, E., Obata, T., Aoshima, S. and Furukawa, J. (1990) Polyaddition of Dithiol Compounds to Divinyl Compounds: The Kinetics of the Model Addition Reaction of Thiophenols to Styrenes. Polymer Journal, 22, 803-813. http://dx.doi.org/10.1295/polymj.22.803

[2] Kobayashi, E., Obata, T., Aoshima, S. and Furukawa, J. (1991) Polymer Preparative Japan. Vol. 40 , E95.

[3] Sato, E.; Yokozawa, T.; Endo, T. (1993) Polyaddition of Diallenes: Radical Polyaddition of Dithiols to 1,4-Bis(allenyloxy)benzene. Macromolecules, 26, 5185-5192. http://dx.doi.org/10.1021/ma00071a031

[4] Sato, E., Yokozawa, T. and Endo, T. (1996) Photopolyaddition of Dithiols to bis(alkoxyallene)s. Journal Polymer Science Part A, 34, 669-672. http://dx.doi.org/10.1002/(SICI)1099-0518(199603)34:4<669::AID-POLA13>3.0.CO;2-M

[5] Koizumi, T., Yoshioka, N. and Endo, T. (1994) Novel Radical Ring-Opening Polyaddition of Dithiols to Bis(isopropenylepoxyethyl)benzene. Macromolecules, 27, 1284-1285. http://dx.doi.org/10.1021/ma00083a032

[6] Podkoscielny, W. and Kultys, A. (1976) Linear Polythioesters. I. Products of Interfacial Polycondensation of 4,4'-Di (mercaptomethyl)benzophenone with Terephthaloyl, Isophthaloyl, and Phthaloyl Chlorides. Journal Polymer Science Polymer Chemistry Edtion, 14, 655-662. http://dx.doi.org/10.1002/pol.1976.170140313

[7] Podkoscielny, W. and Kultys, A. (1984) Linear Polythioesters. VII. ${ }^{\dagger}$ Products of Interfacial Polycondensation of 1,4-Di(mercaptomethyl)-2,3,5,6-tetramethylbenzene with Some Aliphatic acid Dichlorides. Journal Polymer Science Polymer Chemistry Edtion, 22, 1025. http://dx.doi.org/10.1002/pol.1984.170220503

[8] Podkoscielny, W. and Szubinska, S. (1986) Linear Polythioesters. XI. ${ }^{\dagger}$ Products of Polycondensation of Some Isomeric Di(mercaptomethyl)dimethylbenzenes with Isophthaloyl and Terephthaloyl Chlorides. Journal Applied Polymer Science, 32, 3277-3283. http://dx.doi.org/10.1002/app.1986.070320130

[9] Podkoscielny, W. and Szubinska, S. (1988) Linear Polythioesters. XIII. ${ }^{\dagger}$ Products of Polycondensation of Isomeric Di(mercaptomethyl)-dimethylbenzenes with Adipoyl and Sebacoyl Chlorides. Journal Applied Polymer Science, 35, 85-93. http://dx.doi.org/10.1002/app.1988.070350108

[10] Podkoscielny, W., Tarasiuk, B. (1993) Linear Polythioesters, XXIII. Products of Interfacial Polycondensation of 4,4’Dimercaptobiphenyl with acid Dichlorides. Die Angewandte Makromolekulare Chemie, 207, 173-186. http://dx.doi.org/10.1002/apmc.1993.052070116

[11] Podkoscielny, W. and Rudz, W. (1993) Linear polythioesters-XXIV. Products of Interfacial Polycondensation of Bis(4-mercaptomethylphenyl)sulphone with Some Aliphatic and Phthaloyl Dichlorides. European Polymer Journal, 29, 1115-1122. http://dx.doi.org/10.1016/0014-3057(93)90318-A 
[12] Shaffer, T. and Percec, V. (1986) Functional Polymers and Sequential Copolymers by Phase Transfer Catalysis. XIX. Thermotropic Polythioethers and Copolythioethers Based on 4,4'-Dithiolbiphenyl. Journal Polymer Science Polymer Chemistry Edition, 24, 451-458. http://dx.doi.org/10.1002/pola.1986.080240305

[13] Tager, A. (1972) Physical Chemistry of Polymers. Mir, Moscow.

[14] Perrian, D.D., Armarego, W.L.F. and Perrin, D.R. (1980) Purification of Laboratory Chemicals. 2nd Edition, Pergamon Press, New York.

[15] Higashi, F., Yamada, Y. and Hoshio, A. (1984) Direct Polycondensations of Hydroxybenzoic Acids by Use of Diphenyl Chlorophosphate in the Presence of N,N-Dimethylformamide. Journal Polymer Science Polymer Chemistry Edition, 22, 2181-2187. http://dx.doi.org/10.1002/pol.1984.170220919

[16] Higashi, F., Hlashimo, T. and Takahashi, I. (1986) Preparation of Aromatic Polyesters by Direct Polycondensation with Thionyl Chloride in Pyridine. Journal Polymer Science Polymer Chemistry Edition, 24, 97-102.

[17] Higashi F. and Hlashimo,T. (1986) Direct Polycondensation of Hydroxybenzoic Acids with Thionyl Chloride in Pyridine. Journal Polymer Science Polymer Chemistry Edtion, 24, 1697-1703. http://dx.doi.org/10.1002/pola.1986.080240726

[18] Mikroyannidis, J.A. (1988) New Styrylpyridine-Based Polyesters and Polyurethanes. European Polymer Journal, 24, 1093-1098. http://dx.doi.org/10.1016/0014-3057(88)90070-5 